\title{
miR-126/VCAM-1 regulation by naringin suppresses cell growth of human non-small cell lung cancer
}

\author{
MINGJIU CHEN ${ }^{1}$, WEILIN PENG ${ }^{1}$, SHIFENG HU ${ }^{1}$ and JIE DENG ${ }^{2}$ \\ ${ }^{1}$ Department of Thoracic Surgery, The Second Xiangya Hospital, Central South University, Changsha, Hunan 410011; \\ ${ }^{2}$ Department of Respiratory Medicine, The First Hospital of Changsha, Changsha, Hunan 410005, P.R. China
}

Received June 14, 2016; Accepted October 12, 2017

DOI: $10.3892 /$ ol.2018.9204

\begin{abstract}
Certain studies have indicated that naringin possesses various pharmacological activities including anti-aging, anti-oxidation, anticancer, cardiovascular and cerebrovascular disease prevention, in addition to anti-hepatic effects. The present study explores the anticancer effect of naringin on human small cell lung cancer H69AR cells. Cell growth and apoptosis rates of H69AR cells were measured by MTT or flow cytometry, which demonstrated naringin suppressed cell growth and induced apoptosis of H69AR cells. MicroRNA (miR)-126 expression and levels of phosphorylated protein kinase $\mathrm{B}(\mathrm{AKT})$, mechanistic target of rapamycin (mTOR), nuclear factor (NF)- $\kappa \mathrm{B}$ and vascular cell adhesion molecule 1 (VCAM-1) proteins were detected by quantitative polymerase chain reaction and western blotting. It was identified that naringin increased miR-126 expression and suppressed the phosphorylation of AKT, mTOR, NF- $\mathrm{BB}$ and VCAM-1 proteins in H69AR cells. Suppression of miR-126 expression reduced the anticancer effects of naringin on H69AR cells, reversed the naringin-induced reduction of phosphoinositide 3-kinase/AKT/mTOR, and suppressed VCAM-1 protein levels. However, close of miR-126 expression did not affect the levels of NF- $\kappa$ B protein in H69AR cells. In summary, naringin exhibits its anti-cancer effect by suppressing cell growth of small cell lung cancer cells through miR-126/VCAM-1 signaling pathway.
\end{abstract}

\section{Introduction}

Small cell lung cancer (SCLC) is a type of invasive malignant tumor, accounting for $\sim 13 \%$ of lung cancer (1). It is characterized by marked invasiveness, high grade malignancy, high

Correspondence to: Dr Jie Deng, Department of Respiratory Medicine, The First Hospital of Changsha, 311 Yingpan Road, Changsha, Hunan 410005, P.R. China

E-mail: dui84130013229@126.com

Key words: naringin, small cell lung cancer, microRNA-126, vascular cell adhesion protein-1, phosphoinositide 3-kinase/protein kinase $\mathrm{B} /$ mechanistic target of rapamycin risk of early metastasis and poor prognosis. High metastases ability and relapse following drug resistance are the primary causes for this poor prognosis in patients with SCLC (2). The initiation, progression, treatment resistance and relapse of tumors are associated with metastasis. These are the primary factors responsible for the intractable and stubborn properties of this type of tumor (3). Identification of biological characteristics and exploration of novel targets for diagnosis and treatment methods are of important theoretical significance and clinical value.

MicroRNA (miRNA) are single stranded noncoding nuclear acid molecules with a length of 18-24 nucleotides and high levels of evolutionary conservation. Certain miRNAs constitute the RNA-induced silencing complex (RISC), together with other proteins (4). Subsequent to the RISC protein complex combining with mRNA, the complex will begin to splice mRNA or block mRNA translation, consequently causing mRNA degradation or translation inhibition (5). It participates in a variety of important biological processes including cell differentiation, proliferation and apoptosis, hormone secretion and tumor formation in plants and animals (6). The results of bioinformatics predictions have indicated that each miRNA may regulate 1,000 s of target genes (7). miRNAs have potential effects on almost every genetic pathway and regulate different biological processes.

An adhesion molecule is a bio-macromolecule that mediates the binding between cells, and between cells and the extracellular matrix, and serves an important role in maintaining the normal structures of tissues and homeostasis of various pathophysiological processes including the inflammatory and immune responses, blood coagulation, formation of thrombosis and the invasion and metastasis of malignant tumors (8). Based on their structures, adhesion molecules may be grouped into various families: The integrin family, selectin family, immunoglobulin superfamily, E-cadherin family and other families, among which intercellular adhesion molecule-1 (ICAM-1) and vascular cell adhesion molecule-1 (VCAM-1) are the most important types, and serve vital roles in regulating the binding between cells, and between cells and the extracellular matrix (9). In addition, ICAM-1 and VCAM-1 are also involved in a number of physiological and pathological processes including the immune response, inflammation and the development and metastasis of tumors (10). 
A previous study indicated that the antioxidant activity of naringin (Fig. 1) is markedly increased compared with that of compounds from Pomelo (11). A further study suggested that naringin exhibits anti-atherosclerosis and anticancer effects, and also improves myocardial ischemia and immune regulation (12). Naringin exhibits notable anti-oxidant, anti-inflammatory and anti-tumor effects (13). The present study hypothesized that the anticancer effect of naringin involves the suppression of cell growth and induction of apoptosis in human SCLC cells, and analyzed the potential mechanisms of action.

\section{Materials and methods}

Cell culture. The human H69AR SCLC cell line was purchased from the Affiliated Hospital of Hebei University (Baoding, China), and grown in RPMI-1640 medium (Thermo Fisher Scientific, Inc., Waltham, MA, USA) supplemented with $10 \%$ FBS (Thermo Fisher Scientific, Inc.) and penicillin/streptomycin at $37^{\circ} \mathrm{C}$ in an environment containing $5 \% \mathrm{CO}_{2}$.

Cell proliferation assay. A total of $1.2 \times 10^{6} \mathrm{H} 69 \mathrm{AR}$ cells/well were plated in 6-well plates and treated with 6,12 and $25 \mu \mathrm{g} / \mathrm{ml}$ naringin for $24 \mathrm{~h}$ at $37^{\circ} \mathrm{C}$. The old medium was then removed, and $200 \mu \mathrm{MTT}(0.5 \mu \mathrm{mol} / \mathrm{l})$ was added into the wells and incubated for $4 \mathrm{~h}$ at $37^{\circ} \mathrm{C}$. A total of $150 \mu \mathrm{l}$ dimethyl sulfoxide was added into each well and shaken for $20 \mathrm{~min}$. The absorbance was detected using a microplate reader (SpectraMax ${ }^{\circledR}$ M2; Molecular Devices, LLC, Sunnyvale, CA, USA) and read at a wavelength of $570 \mathrm{~nm}$.

Apoptosis and flow cytometry. A total of $1.2 \times 10^{6}$ H69AR cells/well were plated in 6-well plates and treated with 6 , 12 and $25 \mu \mathrm{g} / \mathrm{ml}$ naringin for $24 \mathrm{~h}$. $\mathrm{H} 69$ cells was washed and collected via centrifugation $2,000 \mathrm{x}$ g for $5 \mathrm{~min}$ at $4^{\circ} \mathrm{C}$. $\mathrm{H} 69$ cells were fixed with $4 \%$ paraformaldehyde for $15 \mathrm{~min}$ at room temperature and re-suspended using buffer solution (eBioscience; Thermo Fisher Scientific, Inc.), and then $5 \mu$ l Annexin V (eBioscience; Thermo Fisher Scientific, Inc.) was added into every well and stained for $30 \mathrm{~min}$ in darkness, on ice at $37^{\circ} \mathrm{C}$, and $\mathrm{H} 69$ cells were stained with $10 \mu \mathrm{l}$ propidium iodide in darkness for $15 \mathrm{~min}$ at room temperature. Cells were measured using a FACSCalibur flow cytometer (BD Biosciences, Franklin Lakes, NJ, USA) and analyzed using Flowjo 7.6.1 (FlowJo, LLC, Ashland, OR, USA).

Reverse transcription-quantitative polymerase chain reaction $(R T-q P C R)$. A total of $2 \times 10^{6}$ cells/well were plated in 6-well plates and treated with 6,12 and $25 \mu \mathrm{g} / \mathrm{ml}$ naringin for $24 \mathrm{~h}$. Total RNA was isolated from treated H69 cells using TRIzol ${ }^{\circledR}$ reagent (Invitrogen; Thermo Fisher Scientific, Inc.) and the expression level of miR-126 was determined by a RT-qPCR assay. cDNA was transcribed using High-Capacity cDNA Reverse Transcription kit (Applied Biosystems; Thermo Fisher Scientific, Inc.). qPCR was performed with FastStart SYBR Green Master Mix (Invitrogen; Thermo Fisher Scientific, Inc.) and ABI 7900 HT sequence detection system. The PCR thermocycler conditions used were: $95^{\circ} \mathrm{C}$ for $10 \mathrm{~min}$, followed by 35 cycles of $45 \mathrm{sec}$ at $95^{\circ} \mathrm{C}, 45 \mathrm{sec}$ at $60^{\circ} \mathrm{C}$ and $60 \mathrm{sec}$ at $72^{\circ} \mathrm{C}$, then samples were stored at $4^{\circ} \mathrm{C}$ until use. The primer sequences used are as follows: microRNA-126, forward, 5'-UCGUAC CGUGAGUAAUAAUGCG-3' and reverse, 5'-CAUUAU UACUUUUGGUACGCG-3'; U6, forward, 5'-ATTGGAACG ATACAGAGAAGATT-3' and reverse, 5'-TGGTGAAGA CGCCAGTGGA-3'. The $2^{-\Delta \Delta C q}$ method was used to measure microRNA-126 expression (14).

Western blotting. Cells were collected and resuspended in RIPA assay (Beyotime Institute of Biotechnology) for $20 \mathrm{~min}$ on ice. The cell mixture was centrifuged at $12,000 \times \mathrm{g}$ at $4{ }^{\circ} \mathrm{C}$ for $10 \mathrm{~min}$, and the supernatants were collected to determine the protein concentration using Enhanced BCA Protein Assay Kit (catalog no., P0009, Beyotime Institute of Biotechnology). A total of $50 \mathrm{mg}$ of protein lysates were separated in $10 \%$ SDS-PAGE and blotted onto polyvinylidene difluoride membranes (Bio-Rad Laboratories, Inc.). The membranes were blocked with 5\% non-fat milk at room temperature for $1 \mathrm{~h}$, and incubated with the appropriate dilution of each primary antibody: Phosphoinositide 3-kinase (PI3K; cat no. sc-7174; 1:500), phosphorylation protein kinase B (p-AKT; cat no. sc-7985-R; 1:500), phosphorylation mechanistic target of rapamycin (p-mTOR; cat no. sc-101738; 1:1,000), nuclear factor (NF)- $\mathrm{B}$ (cat no. sc-109; 1:500), VCAM-1 (cat no. sc-8304; 1:500) and GAPDH (cat no. sc-25778; 1:1,000; all from Santa Cruz Biotechnology, Inc., CA, USA) overnight at $4^{\circ} \mathrm{C}$. The membranes were probed with anti-rabbit horseradish peroxidase-conjugated secondary antibodies (cat no. sc-2004; 1:5,000; Santa Cruz Biotechnology, Inc.) for $1 \mathrm{~h}$ at $37^{\circ} \mathrm{C}$. The protein bands were visualized using BeyoECL Star (Beyotime Institute of Biotechnology) and analyzed using Image_Lab_3.0 software (Bio-Rad Laboratories, Inc.).

Transfection with miR-126. A total of $2 \times 10^{6}$ cells/well were plated in 6-well plates and transfected with miR-126 (5'-UCG UACCGUGAGUAAUAAUGCG-3', Sangon Biotech Co., Ltd., Shaghai, China) and control miRNA mimics (5'-CAGUAC UUUUGUGUAGUACAA-3', Sangon Biotech Co., Ltd.) at a final concentration of $50 \mathrm{nM}$ using Lipofectamine ${ }^{\circledR} 2000$ (Invitrogen; Thermo Fisher Scientific, Inc.) for $6 \mathrm{~h}$ at $37^{\circ} \mathrm{C}$. Then, the old RPMI-1640 medium was removed and new RPMI-1640 medium (Thermo Fisher Scientific, Inc., Waltham, MA, USA) supplemented with $25 \mu \mathrm{g} / \mathrm{ml}$ naringin, was introduced following transfection complexes for $24 \mathrm{~h}$.

Statistical analysis. Data were presented as the mean \pm standard deviation. Data were analyzed via one-way analysis of variance with Tukey's post-hoc test using SPSS software, version 16.0 (SPSS, Inc., Chicago, IL, USA). $\mathrm{P}<0.05$ was considered to indicate a statistically significant difference.

\section{Results}

Anticancer effect of naringin on cell proliferation of the $\mathrm{H} 69$ cell line. To understand the anticancer effect of naringin, namely the suppression of cell growth in small cell lung cancer cells, the SCLC H69 cell line was treated with 6, 12 and $25 \mu \mathrm{g} / \mathrm{ml}$ naringin for $24 \mathrm{~h}$. The results demonstrated that naringin suppressed cell growth of the small cell SCLC lung cancer H69 cell line in a dose-dependent manner (Fig. 2). 


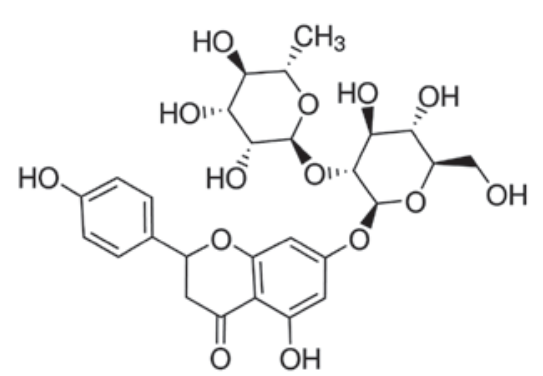

Figure 1. Chemical structure of naringin.

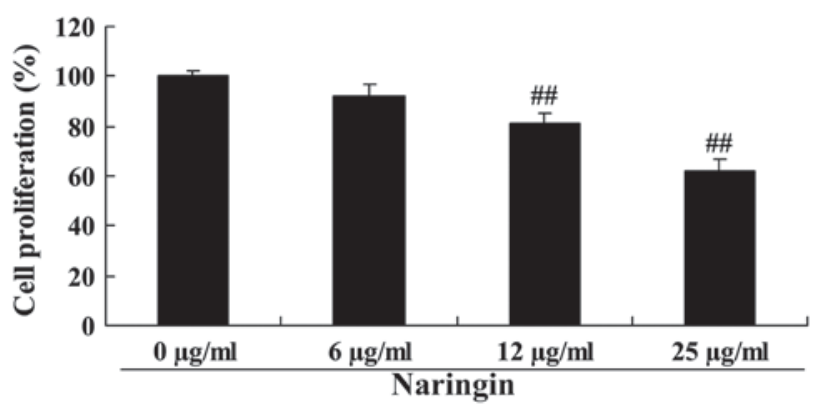

Figure 2. Anticancer effect of naringin on cell proliferation in H69 cells. Treatment with naringin decreased cell proliferation. ${ }^{\# \#} \mathrm{P}<0.01$ vs. $0 \mu \mathrm{g} / \mathrm{ml}$ naringin-treated group.

In particular, the suppression of cell growth in the SCLC H69 cell line was statistically significant following treatment with 12 or $25 \mu \mathrm{g} / \mathrm{ml}$ naringin for $24 \mathrm{~h}$, compared with control.

Anticancer effect of naringin on apoptosis of the H69 cell line. To investigate the inhibitory effects of naringin on SCLC H69 cell apoptosis, levels of apoptosis were detected using flow cytometry. Naringin-induced cell apoptosis of the SCLC H69 cell line was observed, which was statistically significant when treated with 12 or $25 \mu \mathrm{g} / \mathrm{ml}$ naringin at $24 \mathrm{~h}$, compared with control (Fig. 3).

Anticancer effect of naringin on miR-126 in the H69 cell line. To additionally evaluate the mechanism of the anti-tumor effects of naringin in the SCLC H69 cells, the expression of miR-126 was measured using RT-qPCR. As demonstrated in Fig. 4, the expression of miR-126 was markedly increased following treatment with 12 or $25 \mu \mathrm{g} / \mathrm{ml}$ naringin.

Anticancer effect of naringin on PI3K/AKT, mTOR, NF- $\kappa B$ and VCAM-1 in H69 cells. To verify the mechanism of action of naringin on the PI3K/AKT pathway in $\mathrm{H} 69$ cells, PI3K/AKT, mTOR, NF- $\mathrm{BB}$ and VCAM-1 protein levels were measured using western blotting. Compared with the $0 \mu \mathrm{g} / \mathrm{ml}$ naringin-treated group, PI3K, phosphorylated (p)-AKT, p-mTOR, NF- $\kappa$ B and VCAM-1 protein levels were significantly suppressed by treatment with 12 or $25 \mu \mathrm{g} / \mathrm{ml}$ naringin (Fig. 5).

Overexpression of miR-126 on the effect of naringin on cell growth. To identify the role of miR-126 in the effect of naringin on cell growth of H69 cells, miR-126 and negative control

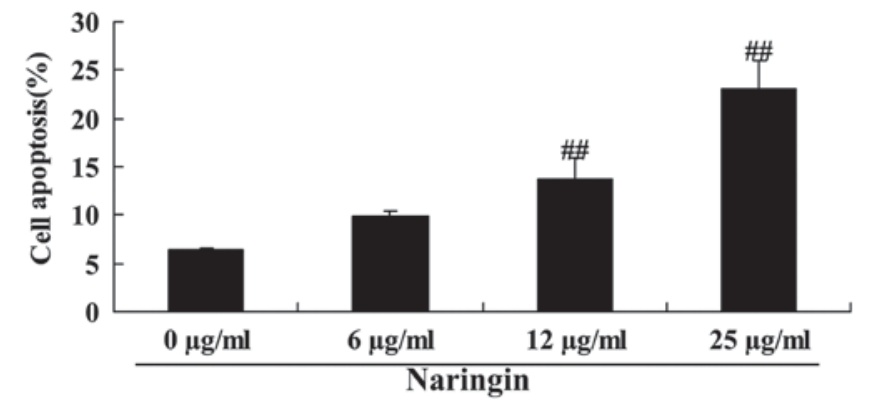

Figure 3. Anticancer effect of naringin on apoptosis in H69 cells. Treatment with naringin resulted in increased cell apoptosis. ${ }^{\# \#} \mathrm{P}<0.01 \mathrm{vs} .0 \mu \mathrm{g} / \mathrm{ml}$ naringin-treated group.

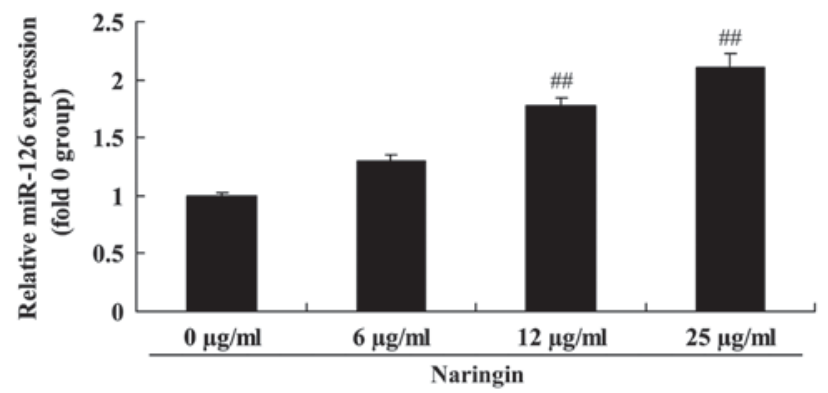

Figure 4. Anticancer effect of naringin on miR-126 expression in H69 cells. Treatment with naringin resulted in increased mRNA expression of miR-126. ${ }^{\# \#} \mathrm{P}<0.01$ vs. $0 \mu \mathrm{g} / \mathrm{ml}$ naringin-treated group. miR, microRNA.

miRNA were transfected into H69 cells. When compared with an additional small interfering control, the expression of miR-126 was markedly increased in H69 cells (Fig. 6). miR-126 overexpression augmented the inhibitory effect of naringin on cell growth in H69 cells, compared with negative control (Fig. 6).

Overexpression of miR-126 on the effect of naringin on PI3K/AKT, mTOR, NF- $K B$ and VCAM-1 signaling pathway. The role of miR-126 in p-AKT, p-mTOR, NF- $\kappa \mathrm{B}$ and VCAM-1 protein in H69 cells was investigated. As demonstrated in Fig. 7, the decrease in the phosphorylated protein levels suggested that the activity of the PI3K/AKT/mTOR signaling pathway in the $25 \mu \mathrm{g} / \mathrm{ml}$ naringin-treated group or negative control was decreased compared with of $0 \mu \mathrm{g} / \mathrm{ml}$ naringin-treated group. Notably, the expression of p-AKT, p-mTOR, NF-kB and VCAM-1 protein levels observed in the miR-126 overexpression group was markedly inhibited in H69 cells treated with naringin, compared with that of the negative control (Fig. 7).

\section{Discussion}

Lung cancer is a highly malignant neoplastic disease. In addition, its morbidity rate has demonstrated an increasing trend year-on-year (5). In previous years, with the increase in anti-smoking efforts, its morbidity has demonstrated a decreasing trend. According to statistics from the United States of America, there were $\sim 172,570$ patients with lung cancer, including 93,010 males and 79,560 females, ranking 
A

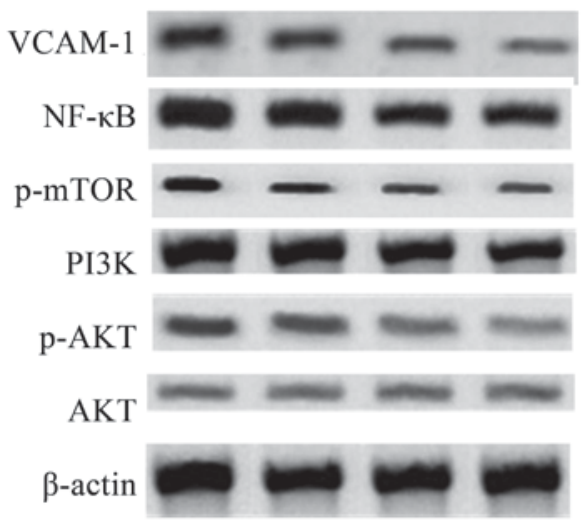

$0 \mu \mathrm{g} / \mathrm{ml} 6 \mu \mathrm{g} / \mathrm{ml} 12 \mu \mathrm{g} / \mathrm{ml} 25 \mu \mathrm{g} / \mathrm{ml}$

Naringin

C

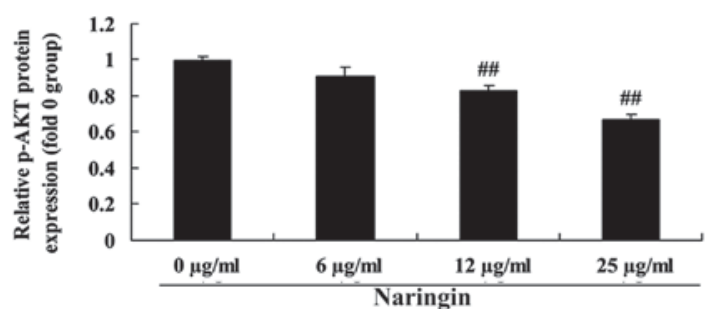

E

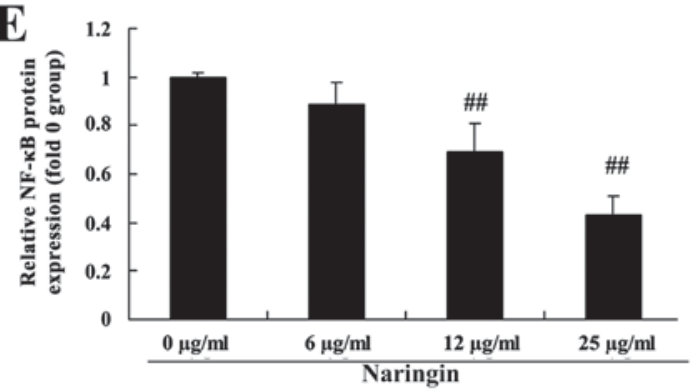

B

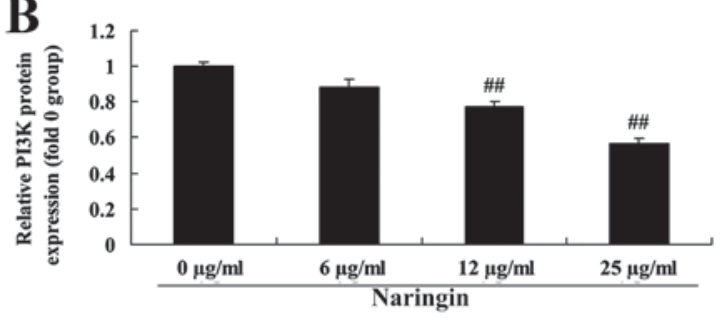

D

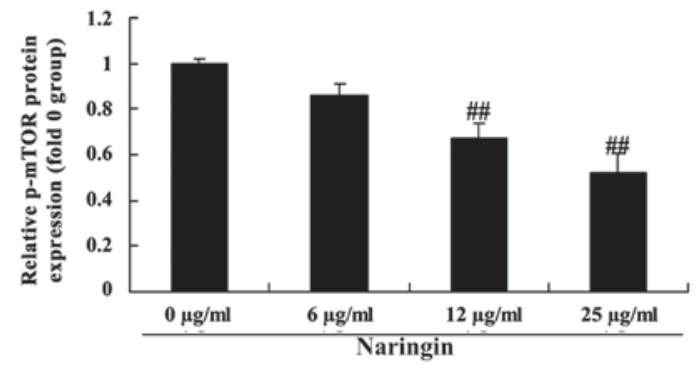

F

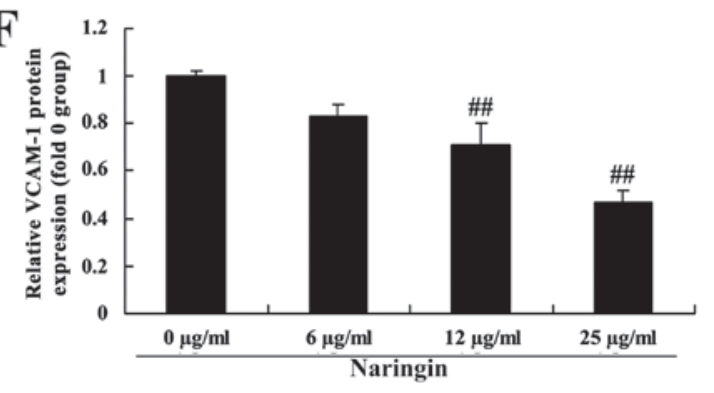

Figure 5. Anticancer effect of naringin on PI3K/AKT, mTOR, NF- $\mathrm{KB}$ and VCAM-1 levels in H69 cells. (A) Western blot analysis of the protein levels of PI3K, p-AKT, p-mTOR, NF-kB and VCAM-1 and statistical analysis of the protein levels of (B) PI3K, (C) p-AKT, (D) p-mTOR, (E) NF-kB and (F) VCAM-1. ${ }^{\# \#} \mathrm{P}<0.01$ vs. $0 \mu \mathrm{g} / \mathrm{ml}$ naringin-treated group. VCAM-1, vascular cell adhesion molecule 1 ; NF- $\mathrm{\kappa B}$, nuclear factor $\mathrm{\kappa B}$; mTOR, mechanistic target of rapamycin; PI3K, phosphoinositide 3-kinase; AKT, protein kinase B; p, phosphorylated.

A

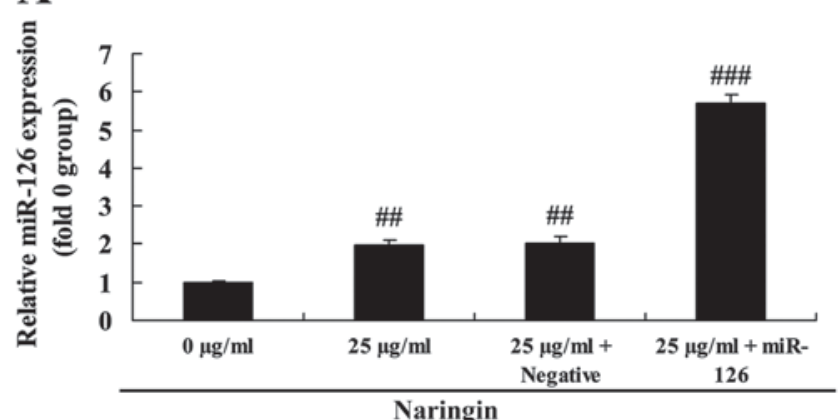

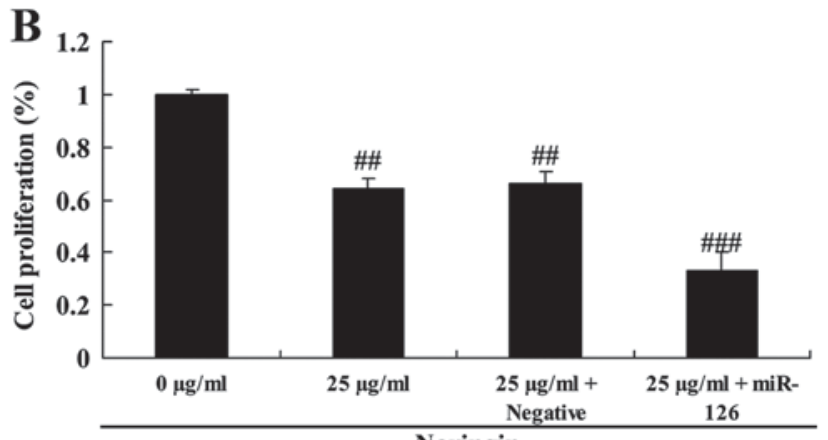

Naringin

Figure 6. Overexpression of miR-126 on the effect of naringin on cell growth. The (A) miR-126 expression and (B) cell proliferation rates in miR-126-overexpressing cells. ${ }^{\# \#} \mathrm{P}<0.01$ vs. $0 \mu \mathrm{g} / \mathrm{ml}$ naringin-treated group; ${ }^{\# \#} \mathrm{P}<0.01 \mathrm{vs.} 25 \mu \mathrm{g} / \mathrm{ml}$ naringin treated group. miR, microRNA; Negative, negative mimics group. 
A
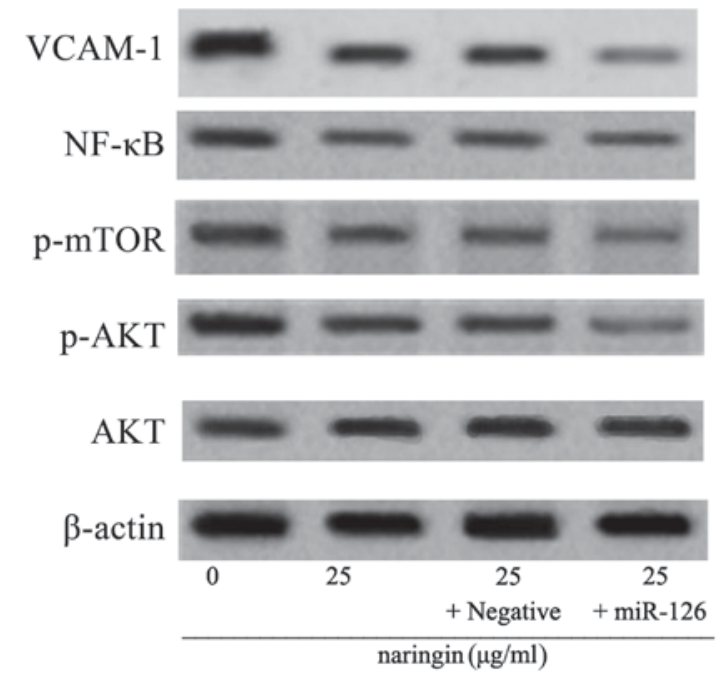

C

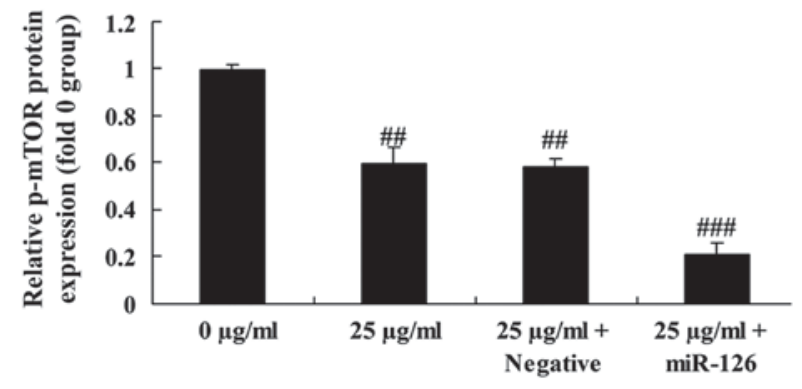

B

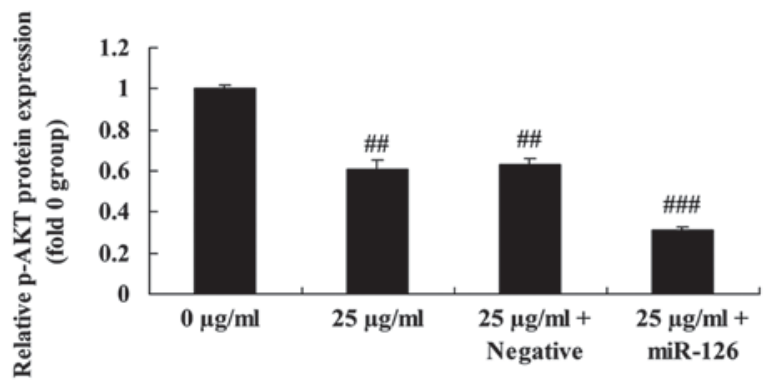

D

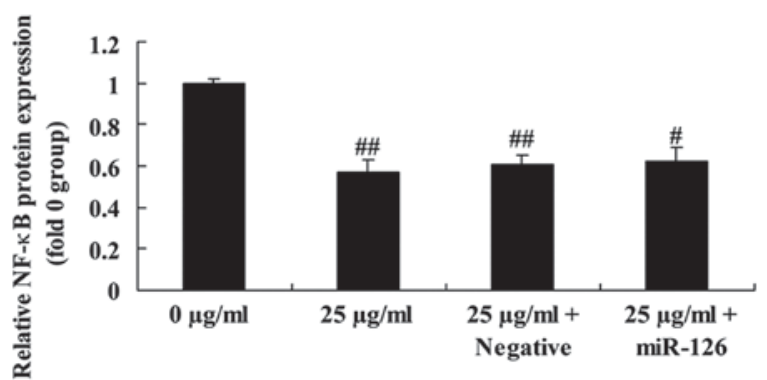

$\mathbf{E}$

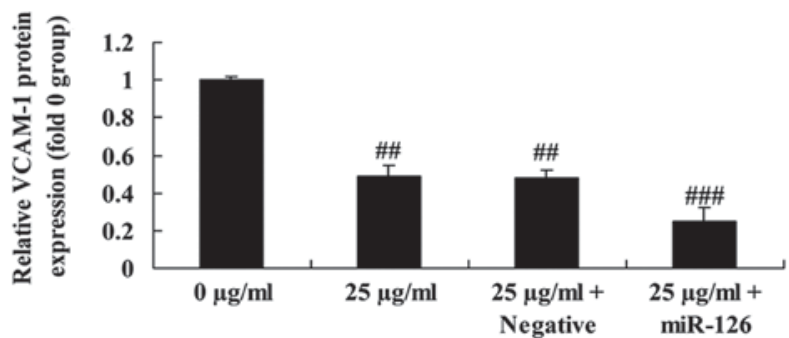

Figure 7. Overexpression of miR-126 on the effect of naringin on PI3K/AKT, mTOR, NF-кB and VCAM-1 protein levels. The protein levels of p-AKT, NF- $\mathrm{kB}$ and VCAM-1 using (A) western blot analysis and statistical analysis for (B) p-AKT, (C) mTOR, (D) NF- $\mathrm{kB}$ and (E) VCAM-1. ${ }^{*} \mathrm{P}>0.05 \mathrm{vs} .25 \mu \mathrm{g} / \mathrm{ml}$ naringin-treated group; ${ }^{\# \#} \mathrm{P}<0.01 \mathrm{vs.} 0 \mu \mathrm{g} / \mathrm{ml}$ naringin-treated group; ${ }^{\# \# /} \mathrm{P}<0.01 \mathrm{vs} .25 \mu \mathrm{g} / \mathrm{ml}$ naringin-treated group. VCAM-1, vascular cell adhesion molecule 1; NF- $\mathrm{kB}$, nuclear factor $\mathrm{\kappa B}$; mTOR, mechanistic target of rapamycin; PI3K, phosphoinositide 3-kinase; AKT, protein kinase B; p, phosphorylated; miR, microRNA; Negative, negative mimics group.

second among all incident tumor diseases (15). Of all cancer mortalities in the USA in that year, males with lung cancer accounted for $31 \%$ and females for $27 \%$ (16). According to a study from the World Health Organization in 2000, the global mortalities from lung cancer accounted for $19 \%$ of all mortalities from malignant tumors, and it was the most common cause of malignant tumor mortality (17). To the best of the author's knowledge, the present study demonstrated for the first time that the anticancer effect of naringin involved the suppression of cell proliferation and the induction of apoptosis in $\mathrm{H} 69$ cells.
Previous studies indicate that naringin suppressed cell growth of HeLa cervical cancer cells (18), human triple-negative breast cancer cells (19) and P388 cells (20). Therefore, it is hypothesized that naringin may be used as an effective anticancer agent for therapy in lung cancer.

miRNA serve an important regulating role in cell growth, differentiation, apoptosis, fat metabolism and other cellular processes in plants and animals (5). Abnormal miRNA expression is closely associated with the development of human tumors. It may function as an oncogene or tumor 
suppressor gene during tumorigenesis (4). High expression levels of miR-16 in SCLC have been verified by applying qPCR methods, and its potential specific target genes have been indicated (21). The present study identified that pretreatment with naringin activated miR-126 expression in the H69 cell line, and Tan et al (22) suggested that naringin suppresses cell growth of chondrosarcoma migration via activation of miR-126. These results indicate that naringin may be a novel and useful anticancer agent for lung cancer therapy that functions through miR-126 expression.

In previous years, the effects of the PI3K/Akt/mTOR signaling pathway on human tumors have been of primary research concern (23). Activation of the PI3K/Akt/mTOR signaling pathway commonly occurs in human tumors (24) through a variety of mechanisms, including gene mutation, reduction of the expression of the cancer suppressor gene Phosphatase and tensin homolog, mutation or amplification of PI3K, mutation or amplification of Akt and gene receptor activation (25). In addition, the activation of PI3K/Akt/mTOR signaling pathway may lead to poor prognostic effects in a variety of tumors. It may cause drug resistance, reverse drug resistance inhibition of the pathway and improve in vitro and in vivo chemotherapy and radiation therapy effects (26). Consequently, in-depth studies on the detailed mechanisms of this pathway are required. In the present study, it was observed that naringin suppressed the PI3K/Akt/mTOR and $\mathrm{NF}-\kappa \mathrm{B}$ signaling pathways and activated miR-126 expression in $\mathrm{H} 69$ cells. Concurrently, it was also identified that overexpression of miR-126 enhanced the naringin-mediated suppression of cell proliferation and PI3K/Akt/mTOR signaling pathway, however did not affect the NF- $\mathrm{NB}$ signaling pathway. Lee et al (27) suggested that naringin inhibits the PI3K/AKT/mTOR pathway in tumor necrosis factor- $\alpha$-treated vascular smooth muscle cells.

The invasion and metastases of malignant tumors are complicated biological phenomena, in which cell adhesion serves a vital role (8). VCAM-1 was activated by inflammation (8). In addition, it is also expressed in dendritic cells, including macrophages and placental trophoblastic cells, B-lymphocytes, smooth muscle cells, fibroblast cells and certain epithelial cells of the kidney (28). VCAM-1 is involved in a variety of biological processes, with a wide range of biological functions, including the adhesion of white blood cells, regulation of inflammatory response, activation and transduction of signals, proliferation and differentiation of cells and tissues, immune response, mobilization of hematopoietic stem cells and other important physiological and pathological processes (29). In particular, numerous studies have verified that VCAM-1 is highly expressed in tumors, and it has been demonstrated that a high level of VCAM-1 expression is present in the tissues and blood samples of breast carcinoma, nasopharyngeal carcinoma and liver carcinoma (30).

In conclusion, the present study identified the anticancer effect of naringin; that it suppresses cell growth and induces apoptosis in SCLC cells through the miR-126/PI3K/AKT/mTOR pathway, potentially through the overexpression of miR-126. Additional studies are required to understand the anticancer effect of naringin in the growth and apoptosis of tumors in vivo.

\section{Acknowledgements}

Not applicable.

\section{Funding}

No funding was received.

\section{Availability of data and materials}

The analyzed data sets generated during the study are available from the corresponding author on reasonable request.

\section{Authors' contributions}

JD designed the study; MC, WP, SH performed the experiments; JD and MC, analyzed the data; JD wrote the manuscript.

\section{Ethics and consent to participate}

Not applicable.

\section{Patient consent for publication}

Not applicable.

\section{Competing interests}

The authors declare that they have no competing interests.

\section{References}

1. Xue H, Wang H, Liu J, Liu H, Li C, Han L, Lin C, Zhan Q, Zhao Z and Qian H: MTA1 downregulation inhibits malignant potential in a small cell lung cancer cell line. Oncol Rep 33: 885-892, 2015

2. Bremnes RM, Sundstrom S, Aasebø U, Kaasa S, Hatlevoll R and Aamdal S; Norweigian Lung Cancer Study Group: The value of prognostic factors in small cell lung cancer: Results from a randomised multicenter study with minimum 5 year follow-up. Lung Cancer 39: 303-313, 2003.

3. Wood L, Palmer M, Hewitt J, Urtasun R, Bruera E, Rapp E and Thaell JF: Results of a phase III, double-blind, placebo-controlled trial of megestrol acetate modulation of P-glycoprotein-mediated drug resistance in the first-line management of small-cell lung carcinoma. Br J Cancer 77: 627-631, 1998.

4. Barger JF and Nana-Sinkam SP: MicroRNA as tools and therapeutics in lung cancer. Respir Med 109: 803-812, 2015.

5. Che C, Zhang L, Huo J and Zhang Y: RNA interference targeting enhancer of polycombl exerts anti-tumor effects in lung cancer. Int J Clin Exp Pathol 8: 361-367, 2015.

6. Joshi P, Middleton J, Jeon YJ and Garofalo M: MicroRNAs in lung cancer. World J Methodol 4: 59-72, 2014.

7. Huang $Y, H u$ Q, Deng Z, Hang Y, Wang J and Wang K: MicroRNAs in body fluids as biomarkers for non-small cell lung cancer: A systematic review. Technol Cancer Res Treat 13: 277-287, 2014.

8. Ferjančič S, Gil-Bernabé AM, Hill SA, Allen PD, Richardson P, Sparey T, Savory E, McGuffog J and Muschel RJ: VCAM-1 and VAP-1 recruit myeloid cells that promote pulmonary metastasis in mice. Blood 121: 3289-3297, 2013.

9. Huang X, He D, Ming J, He Y, Zhou C, Ren H, He X, Wang C, Jin J, Ji L, et al: High-density lipoprotein of patients with breast cancer complicated with type 2 diabetes mellitus promotes cancer cells adhesion to vascular endothelium via ICAM-1 and VCAM-1 upregulation. Breast Cancer Res Treat 155: 441-455, 2016. 
10. Tas F, Karabulut S, Bilgin E and Duranyildiz D: Serum levels of vascular cell adhesion molecule-1 (VCAM-1) may have diagnostic, predictive, and prognostic roles in patients with lung cancer treated with platinum-based chemotherapy. Tumour Biol 35: 7871-7875, 2014

11. Bharti S, Rani N, Krishnamurthy B and Arya DS: Preclinical evidence for the pharmacological actions of naringin: A review. Planta Med 80: 437-451, 2014.

12. Kanno S, Shouji A, Asou K and Ishikawa M: Effects of naringin on hydrogen peroxide-induced cytotoxicity and apoptosis in P388 cells. J Pharmacol Sci 92: 166-170, 2003.

13. Camargo CA, Gomes-Marcondes MC, Wutzki NC and Aoyama H: Naringin inhibits tumor growth and reduces interleukin- 6 and tumor necrosis factor $\alpha$ levels in rats with Walker 256 carcinosarcoma. Anticancer Res 32: 129-133, 2012.

14. Yang J, Chen L, Ding J, Zhang J, Fan Z, Yang C, Yu Q and Yang J: Cardioprotective effect of miRNA-22 on hypoxia/reoxygenation induced cardiomyocyte injury in neonatal rats. Gene 579: 17-22, 2016.

15. Kawaguchi T, Ando M, Asami K, Okano Y, Fukuda M, Nakagawa H, Ibata H, Kozuki T, Endo T, Tamura A, et al: Randomized phase III trial of erlotinib versus docetaxel as second- or third-line therapy in patients with advanced non-small-cell lung cancer: Docetaxel and Erlotinib Lung Cancer Trial (DELTA). J Clin Oncol 32: 1902-1908, 2014.

16. Gitlitz BJ, Tsao-Wei DD, Groshen S, Davies A, Koczywas M, Belani CP, Argiris A, Ramalingam S, Vokes EE, Edelman M, et al: A phase II study of halichondrin B analog eribulin mesylate (E7389) in patients with advanced non-small cell lung cancer previously treated with a taxane: A California cancer consortium trial. J Thorac Oncol 7: 574-578, 2012.

17. Gohagan J, Marcus P, Fagerstrom R, Pinsky P, Kramer B and Prorok P; Writing Committee, Lung Screening Study Research Group: Baseline findings of a randomized feasibility trial of lung cancer screening with spiral CT scan vs chest radiograph: The Lung Screening Study of the National Cancer Institute. Chest 126: 114-121, 2004

18. Zeng L, Zhen Y, Chen Y, Zou L, Zhang Y, Hu F, Feng J, Shen J and Wei B: Naringin inhibits growth and induces apoptosis by a mechanism dependent on reduced activation of $\mathrm{NF}-\kappa \mathrm{B} / \mathrm{COX}-2$-caspase-1 pathway in HeLa cervical cancer cells. Int J Oncol 45: 1929-1936, 2014
19. Li H, Yang B, Huang J, Xiang T, Yin X, Wan J, Luo F, Zhang L, Li $\mathrm{H}$ and Ren G: Naringin inhibits growth potential of human triple-negative breast cancer cells by targeting $\beta$-catenin signaling pathway. Toxicol Lett 220: 219-228, 2013.

20. Kanno S, Shouji A, Hirata R, Asou K and Ishikawa M: Effects of naringin on cytosine arabinoside (Ara-C)-induced cytotoxicity and apoptosis in P388 cells. Life Sci 75: 353-365, 2004.

21. Zhang W, Zhang Q, Zhang M, Zhang Y, Li F and Lei P: Analysis for the mechanism between the small cell lung cancer and non-small cell lung cancer combing the miRNA and mRNA expression profiles. Thorac Cancer 6: 70-79, 2015.

22. Tan TW, Chou YE, Yang WH, Hsu CJ, Fong YC and Tang $\mathrm{CH}$ : Naringin suppress chondrosarcoma migration through inhibition vascular adhesion molecule-1 expression by modulating miR-126. Int Immunopharmacol 22: 107-114, 2014.

23. Fumarola C, Bonelli MA, Petronini PG and Alfieri RR: Targeting PI3K/AKT/mTOR pathway in non small cell lung cancer. Biochem Pharmacol 90: 197-207, 2014

24. Poornima P, Weng CF and Padma VV: Neferine from Nelumbo nucifera induces autophagy through the inhibition of $\mathrm{PI} 3 \mathrm{~K} / \mathrm{Akt} / \mathrm{mTOR}$ pathway and ROS hyper generation in A549 cells. Food Chem 141: 3598-3605, 2013.

25. Papadimitrakopoulou V: Development of PI3K/AKT/mTOR pathway inhibitors and their application in personalized therapy for non-small-cell lung cancer. J Thorac Oncol 7: 1315-1326, 2012.

26. Choi UJ, Jee BK, Lim Y and Lee KH: KAI1/CD82 decreases Racl expression and cell proliferation through PI3K/Akt/mTOR pathway in H1299 lung carcinoma cells. Cell Biochem Funct 27: 40-47, 2009.

27. Lee EJ, Kim DI, Kim WJ and Moon SK: Naringin inhibits matrix metalloproteinase-9 expression and AKT phosphorylation in tumor necrosis factor-alpha-induced vascular smooth muscle cells. Mol Nutr Food Res 53: 1582-1591, 2009.

28. Visweswaran GR, Gholizadeh S, Ruiters MH, Molema G, Kok RJ and Kamps JA: Targeting rapamycin to podocytes using a Vascular Cell Adhesion Molecule-1 (VCAM-1)-harnessed SAINT-based lipid carrier system. PLoS One 10: e0138870, 2015.

29. Yurdagul A Jr, Sulzmaier FJ, Chen XL, Pattillo CB, Schlaepfer DD and Orr AW: Oxidized LDL induces FAK-dependent RSK signaling to drive NF- $\mathrm{KB}$ activation and VCAM-1 expression. J Cell Sci 129: 1580-1591, 2016.

30. Gong L, Mi HJ, Zhu H, Zhou X and Yang H: P-selectin-mediated platelet activation promotes adhesion of non-small cell lung carcinoma cells on vascular endothelial cells under flow. Mol Med Rep 5: 935-942, 2012. 